\title{
PERFORMANCE EVALUATION OF A THREE- PHASE EMULSION OF JATROPHA BIODIESEL PRODUCED BY PEROXIDATION.
}

\author{
Manjula P.', Manoharan N. ${ }^{2}$, Palanisamy E. ${ }^{3}$, Kannappan R. ${ }^{4}$ \\ ${ }^{1}$ Research Scholar, Department of Chemical Engineering, Sathyabama University, Chennai, India \\ ${ }^{2}$ Sathyabama University, Chennai, India \\ ${ }^{3}$ Sri Sai Ram Engineering College, Chennai, India \\ Email: 'manju•16•2000@yahoo.com
}

\begin{abstract}
Indiscriminate extraction and lavish consumption of fossil fuels have led to reduction in underground based carbon resources. The search for an alternative fuel, which promises a harmonious correlation with sustainable development, energy conservation, management, efficiency and environmental preservation, has become highly pronounced from the refined edible vegetable oil such as Jatropha seed oil by alkaline catalyzed transesterification process. In the study reported herein, Jatropha oil was used as raw oil to produce biodiesel by transesterification reaction accompanied by peroxidation to further improve the fuel properties of the biodiesel. By means of high-speed mechanical homogenizer, the biodiesel product was then emulisified with distilled water and emulsifying surfactant to produce a three phase oil droplets in- water- droplets- in-oil(ie.O/W/O) biodiesel emulsion and an O/W/O emulsion that contained aqeous ammonia, which is a $\mathrm{NO}_{\mathrm{x}}$ inhibitor agent. The prepared biodiesel was then subjected to performance and emission tests in order to evaluate its actual performance, when used as a diesel engine fuel. A single cylinder direct injection diesel engine was used for this work to investigate the engine performance and emission characteristics of the biodiesel, the O/W/O biodiesel emulsion, the O/W/O biodiesel emulsion that contained aqeous ammonia. The brake specifc fuel consumption (BSFC) and brake thermal efficiency (BTE) were calculated from the recorded data. Moreover, the existence of aqeous ammonia in the O/W/O biodiesel emulsion curtails $\mathrm{NO}_{x}$ formation, thus resulting in the lowest $\mathrm{NO}_{x}$ emissions among the four tested fuels in burning the O/W/O biodiesel emulsion that contained aqeous ammonia.
\end{abstract}

Keywords: Biodiesel; Esterification; Engine performance; Emulsion; peroxidation process.

\section{INTRODUCTION}

Use of efficient diesel engines need encouragement in the future since they consume less fuel and significantly reduce potent green house gases like carbon dioxide. Ever increasing diesel consumption, large outflow of foreign exchange and concern for environmental have prompted developing countries like India to search for a suitable environmental friendly alternative to diesel fuel. Recently, we have described a new approach for extraction of oil from plant materials, in general, and soybean in particular[1]. The country has to simultaneously address the issues of energy security, increasing oil prices and large- scale unemployment. It is in this context that development and use of biodiesel from straight vegeatable oils(SVO). Biodiesel which is produced from Jatropha seed oil, can be used as an alternative fuel for diesel engines. The high oxygen content of Jatropha biodiesel not only enhances its burning efficiency, but also generally promotes the formation of more nitrogen oxides $\left(\mathrm{NO}_{*}\right)$ during the burning process. To reduce $\mathrm{NO}_{x}$ inhibitor agents in fuel are considered. The use of biodiesel in conventional diesel engines result in substantial reduction in emission of unburned hydrocarbons, carbon monoxide and particulate.
Like Jatropha curcas may be looked at, the Jatropha seed kernel contains 40-60\% (w/w) oil. [2] Jatropha oil can be directly used in diesel engines as they have a high cetane number and calorific value very close to diesel. Jatropha oil is environment friendly and does not produce Volatile organic Compounds as atmospheric pollutants[3]However, the brake thermal efficiency is inferior to diesel. They also lead to problems of high smoke, $\mathrm{HC}$ and $\mathrm{CO}$ emissions. This is because the high viscosity and low volatility of vegetable oils lead to difficulty in atomizing the fuel and in mixing it with air. Further, gum formation and piston sticking under long-term use due to the presence of oxygen in their molecules and the reactivity of the unsaturated $\mathrm{HC}$ chains are problems with vegetable oils.

Several approaches have been tried by researches to use vegetable oils efficiently in diesel engines. Transesterification of vegetable oil provides a significant reduction in viscosity, thereby enhancing the physical properties. The cetane number is also improved. It has been reported that the methyl ester of vegetable oils offers low smoke levels and high thermal efficiencies than heat vegetable oils. Oil seed crops are potential renewable sources of fuels; peanut, soybean, rapeseed, linseed, sunflower, safflower, coconut and corn oils have been 
used as diesel fuel substitutes in many parts of the world.Vegetable oils are triglycerides and as per ASTM, bio- diesels are mono alkyl esters of long chain fatty acids derived from renewable fats such as oils and animals fats for use in diesel engines.

Transesterification is an effective process of biodiesel production in which straight vegetable oils are treated with Methanol in the presence of catalyst. Catalysts like sodium or potassium hydroxide are generally used[4] Jatropha Curcas is a drought resistant tropical tree and the oil from its seeds has been found useful for medicinal purposes, an insectiside, for soap production and as a fuel substitute. Jatropha curcas oil (SVO) is chemically modified in to biodiesel through a transesterification process. Biodiesel thus obtained has properties close to diesel fuel and is found to be engine friendly.

Jatropha curcas oil as an efficient substitute fuel for diesel engines. Jatropha Linn, (Euphurbiacea) is a genus comprising of 70 species distributed in the tropical and sub- tropical parts of the world of which nine species occur in India. [5-7].Biodiesel from Jatropha oil is free from sulfur and still exhibits excellent lubricity, which is an indication of the amount of wear that occurs between two metal parts covered with the fuel as they come in contact with each other. In spite of several advantages, Jatropha based biodiesel found to emit higher $\mathrm{NO}_{x}$ compared to diesel fuel, Higher $\mathrm{NO}_{x}$ emission from Jatropha biodiesel is probably due to their higher bulk modulus and boiling point.

However, oxygen content of about $10 w t \%$ in biodiesel enhances the formation of nitrogen oxide $\left(\mathrm{NO}_{x}\right)$ when the biodiesel is burned in a combustor. $\mathrm{NO}_{\mathrm{x}}$ emission is a gaseous substance that is harmful to both human and the environment. In humans they irritate the eyes, throat, and respiratory system. Even though some cetane improving additives are capable of reducing $\mathrm{NO}_{x}$, the amount of reduction is reported to be inadequate.

In addition, when $\mathrm{NO}_{x}$ emission react with hydrocarbon with the help of ultraviolet sunlight, photochemical smog is produced; this leads to the damage of the ozone layer in the stratosphere. To reduce the emission of nitrogen oxides, particulate matter (pm), smoke, and other pollutauts, fuel emulsification technique is used. The two components water and oil are inherently immiscible. An emulsion structure of water droplets is developed by oil layers or vice versa by applying mechanical swirling or electromagnetic force to the mixture of water, oil, and a suitable emulsifying agent.

It has been estimated that $10 \%$ water content in the emulsion of water- droplets-in-oil(ie w/o emulsion will reduce the emission of $\mathrm{NO}_{x}$ by about $10 \%$ ). Ammonia has been used in after- treatment equipment such as selective catalyst reduction (SCR) application to curtail $\mathrm{NO}_{x}$ emissions in exhaust gas. To investigate the effect on the reduction of $\mathrm{NO}_{x}$ emissions from diesel engine, aqeous ammonia was added to the dispersed water phase of oildroplets-in-water- droplets-in-oil (ie o/w/0) [8].Jatropha is widely grown in Mexico, Nicaragua, N.E. Thailand and in parts of India. It is now being promoted in southern Africa, Brazil, Mail and Nepal. There are several governments, international organizations, national bodies and NGOs promoting the planting and use of $\mathrm{J}$. curcas of and other oil bearing plants. These include the world Bank, the International Plant Genetic Research Institute, Austrian and German Technical Assistance Programmes, the Rock efeller foundation. Appropriate Technology International and Intemediate Technology Development Group- (USA and UK based NGOs) and the Biomass Users Network (BUN) and plant oil producers association of Zimbabwe [915].Jatropha oil was used as the raw oil to produce biodiesel by transesterfication accompanied with peroxidation technology. An o/w/o biodiesel emulsion and an o/w/o emulision that contained aqeous ammonia were tested by a direct- injection diesel engine to investigate the effects of fuel emulsification and the $\mathrm{NO}_{x}$ inhibitor agent on the engine performance and emission characteristics.

\section{EXPERIMENTAL DETAILS PREPARATION OF BIODIESEL}

Jatropha oil was converted into its methyl ester by the transesterification process. This involves making the triglycerides of Jatropha oil to react with methyl alcohol in the presence of a $\mathrm{NaOH}$ catalyst to produce glyerol and fathy acid ester. Transesterification is a process of producing a reaction of triglyceride and alcohol in presence of catalyst to produce glycerol and ester. Molecular weight of a typical ester molecule is roughly one third that of typical oil molecule and therefore has a lower viscosity[16]. Methanol is extensively used because of its low cost and its physicochemical advantages with triglycerides and alkalies are easily dissolved in it.

Alkali catalyzed transesterification is faster than acid catalyzed transesterification and is most often used commercially. Specified amount $(100 \mathrm{ml})$ of Jatropha oil $(450 \mathrm{ml})$ methanol and $(10 \mathrm{~g})$ sodium hydoxide were taken in a round bottom flask. The contents were stirred till ester formation began. An emulsifying and homogenizing machine was used to stir the mixture for $2 \mathrm{hrs}$ at a speed of $3000 \mathrm{rpm}$ to induce transesterification and the mixture was heated to $70^{\circ} \mathrm{c}$. Then it was allowed to cool overnight without stirring. Two layers are formed. The bottom layer consist of glycerol and top layer was the ester. Fifty wt $\%$ of 
petroleum ether and $0.5 \mathrm{wt} \%$ of distilled water were then added to the coarse biodiesel sequentially to wash away the other impurities. To further improve the fuel properties of the ester layer, a peroxidation process was used. One wt $\%$ of $\mathrm{H}_{2} \mathrm{O}_{2}$ of the ester layer was added and stirred into the biodiesel at a temperature of $60^{\circ} \mathrm{C}$ for $10 \mathrm{~min}$. It attack the "* bonds in the unsaturated carbon bonds of the biodiesel, which attached to the double bonds of the methyl esters, changed to saturated carbon bonds, leading to an improvement of the fuel properties. The biodiesel product was then available for further emulsion preparation[17].

\section{PREPARATION OF BIODIESEL EMULSION}

To prepare the two- phase oil-in-water (o/w) emulsion of biodiesel two commercial surfactan\$-Span 80,a lipophilic surfactant and Tween 80 , a hyhophilic surfactant were used.

The biodiesel to water ratio for preparing water-in-oil emulsions was fed at o/w=10/90 plus $1 \%$ Tween 80 of the biodiesel as the emulsifier on a volumetric base.

By adding $1 \%$ of Tween 80 of the biodiesel and by using an electromagnetic machine stirring was done until the surfactant was completely mixed with biodiesel. An emulsifying and homogenizing machine of speed range $3000-10,000 \mathrm{rpm}$, was then used to stir the surfactant/ biodiesel mixture at a speed of $8000 \mathrm{rpm}$. Distilled water was fed into the mixture using a metering pump at a rate of $40 \mathrm{~m} / \mathrm{min}$ until all of the distilled water was pumped into the mixture.

The o/w emulsion was used for further preparation of oil-in-water-in-oil (o/w/o) three phase emulsion. The biodiesel was then mixed with span 80 surfactant by an electro magnetic machine until the surfactant/biodiesel mixture at a speed of 3000rpm. Simultaneously, the o/w emulsion was fed into the mixture by a metering pump at a rate of $40 \mathrm{ml} / \mathrm{min}$. The stirring of the mixture lasted for 5 min to finalize the preparation of the three phase o/w/o emulsion.

Aqeous ammonia of $5 \mathrm{wt} \%$ was mixed with the surfactant Tween 80 and distilled water to prepare the o/w emulsion. The preparation procedure in the second stage was the same as that for preparing the o/w/o biodiesel emulsion.

\section{TESTING OF ENGINE PERFORMANCE AND EMISSION CHARACTERISTICS}

A single cylinder 4- stroke water cooled diesel engine developing $3.7 \mathrm{KW}$ at $1500 \mathrm{rev}$ min was used for the research work. The engine performance and emission characteristics of the biodiesel and three phase o/w/o biodiesel emulsions were tested by a diesel engine.
Engine details are given in Table 1. The schematic of the experimental set is shown in Fig1. A high speed digital data acquisition system in conjuction with a piezo electric transducer was used for the measurement of cylinder pressure history. An infrared exhaust analyzer was used for the measurement of $\mathrm{HC} / \mathrm{CO}$ in the exhaust for measuring NO, Rosemont Analytical, model 951A chemiluminescent $\mathrm{NO} / \mathrm{NO}$, Analyzer was also utiluzed. Smoke levels were obtained using a Bosch system.

Table 1. Engine Details

\begin{tabular}{|l|l|l|}
\hline 1 & General Details & $\begin{array}{l}\text { Four Stroke Compression } \\
\text { ignition, water cooled, Single } \\
\text { Cylinder engine. }\end{array}$ \\
\hline 2 & Bore \& Stroke & $80 \mathrm{~mm} \times 120 \mathrm{~mm}$ \\
\hline 3 & $\begin{array}{l}\text { Compression } \\
\text { Ratio }\end{array}$ & $15: 1$ \\
\hline 4 & Rated Output & $3.7 \mathrm{KW}$ at 1500 max min-1 \\
\hline 5 & $\begin{array}{l}\text { Injector Opening } \\
\text { Pressure }\end{array}$ & 170 bar \\
\hline
\end{tabular}

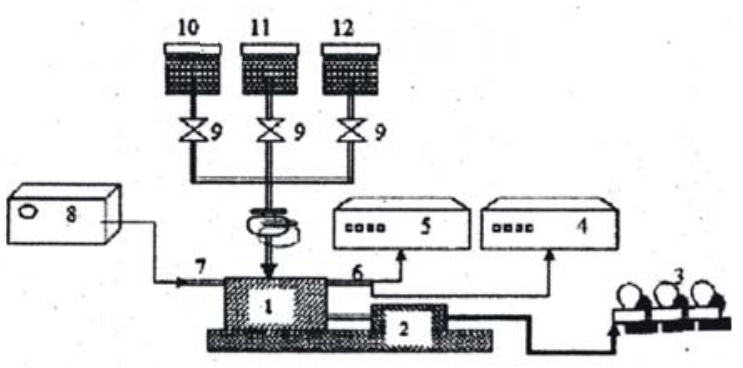

Fig. 1. schematic of the experimental set

Performance and emission tests were carried out in the compression ignition engine. The experimented data generated are documented and presented here using appropriate graphs. These tests are aimed at optimizing the three phase o/w/o biodiesel emulsion that contained aqeous ammonia, for long term engine operation. In each experiment, engine parameters related to thermal performance of the engine such as fuel consumption and applied load are measured. Experiments were carried out on the engine- using diesel as the fuel to provide base line data. The cooling water temperature at the outlet was maintained at $70^{\circ} \mathrm{C}$. The engine speed was held at $1500 \mathrm{rev}$ $\mathrm{min}$ and the power ourput was varied. The biodiesel that was produced from the transesterification reaction accompanied by an additional peroxidation process, the three phase o/w/o biodiesel emulsions, o/w/o biodiesel emulsion that contained aqeous ammonia, and the ASTM No.2D diesel were compared for their engine characteristics. The engine was started in ASTM No.2D diesel fuel and warmed up till cooling water temperature was stabilized. 
The objective of such a study was to asscertain the suitability of these fuels for engine application. Each experimant was carried out three to five times to calculate the mean values of the experimental data. The experimental uncertainties for the exhaust gas temperature, emission of $\mathrm{CO}_{2}$. $\mathrm{NO}_{x}, \mathrm{O}_{2}$, excess air, and $\mathrm{CO}$ were $0.45,1.58,2.95,0.04,2.24$, out 3.51 respectively.

\section{EXPERIMENTAL SET UP RESULTS AND DISCUSSION}

To evaluate the performance parameters, important operating parameters such as engine shaft in rpm, generator output, fuel consumption rate, air flow rate, temperature of engine cooling water and engine exhaust gases were measured and the performance characteristics were determined from their fundamental relations[18]. A series of exhaustive engine tests were carried out on $\mathrm{Cl}$ engine using diesel and other fuels separately at $1500 \mathrm{rpm}[19-20]$. The experimental data generated were calculated, presented through appropriate graphs. Performance and emission test was conducted on various biodiesel in order to optimize for the long term usage in $\mathrm{Cl}$ engines[22].The fuel properties of the four tested fuels are shown in Table 2.

Table 2. Fuel properties of the tested fuels.

\begin{tabular}{|l|c|c|c|c|}
\hline \multicolumn{1}{|c|}{ Properties } & $\begin{array}{c}\text { ASTM No. } \\
\text { 2D diesel }\end{array}$ & $\begin{array}{c}\text { Neat } \\
\text { biodiesel }\end{array}$ & $\begin{array}{c}\text { O/W/O } \\
\text { biodiesel } \\
\text { emulsion }\end{array}$ & $\begin{array}{c}\text { O/W/O biodiesel emulsion } \\
\text { with aqueous ammonia }\end{array}$ \\
\hline $\begin{array}{l}\text { Kinematic Viscosity } \\
\left(\text { CSt at } 40^{\circ} \mathrm{C}\right)\end{array}$ & 2.48 & 4.27 & 7.68 & 6.99 \\
\hline $\begin{array}{l}\text { Gross heating Value } \\
(\text { Callg) }\end{array}$ & 11035 & 9683 & 9373 & 94.69 \\
\hline Specific Gravity & 0.836 & 0.864 & 0.889 & 0.886 \\
\hline Diesel Index & 45 & 51.2 & 50.9 & 43 \\
\hline Cloud Point $\left({ }^{\circ} \mathrm{C}\right)$ & -1 & 1 & -2 & 4 \\
\hline Pour Point $\left({ }^{\circ} \mathrm{C}\right)$ & -16 & -12 & -8 & -3 \\
\hline
\end{tabular}

The large number of water droplets in the o/w/o biodiesel emulsion caused a larger contact surface between the dispersed phase and continous phase of the biodiesel. This led to an increase of both friction and electroststic forces among the water droplets of the dispersed phase in the emulsion, and hence the larger kimematic visosity of the o/w/o biodiesel emulsion is presented in the variation of brake specific fuel consumption with load for different fuels in Fig. 2. The o/w/o biodiesel emulsion appears to have the lowest heating value and the largest kinematic viscosity and specific gravity. In contrast, the ASTM No.2D diesel fuel had the largest heating value and the lowest kinematic viscosity and specific gravity.

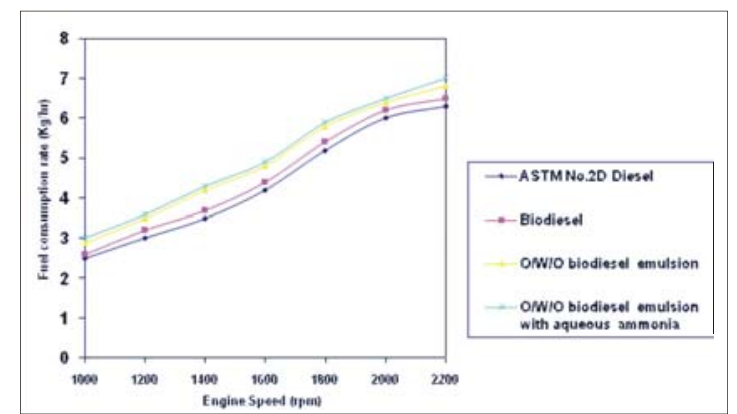

Fig. 2. The variation of fuel consumption rate with load for different fuels

The variation of brake specific fuel consumption with load for different fuels is presented in Fig.3. The specific fuel consumption of o/w/o biodiesel emulsion is higher than that of diesel to attain the same engine torque as the other three fuels because it had the lowest heating value, but the ASTM No.2D diesel fuel had the largest heating value of the tested fuels. It may be noted that the calorific value of o/w/o biodiesel emulsion is $14 \%$ lower than that of diesel.

The variations of brake specific fuel consumption with load for different fuels is presented in Fig3. For all fuels tested, brake specific fuel consumption 13 found to increase with increase in the load. The BSFC will appear when the rate of increase of fuel consumption is larger than that of engine power output with the increase of engine speed. The o/w/o emulsion had a lower heating value, which contained $10 \%$ water content, BSFC must have been larger than both petroleum- based diesel fuel and neat biodiesel to have the same engine power output. Whereas the ASTM No.2D diesel fuel, which had the highest heating value among the four fuels, had the lowest BSFC. In contrast, the o/w/o emulsion had the largest BSFC, primarily it experienced the least micro-explosion and had the lowest heating value, and thus the largest fuel consumption rate.

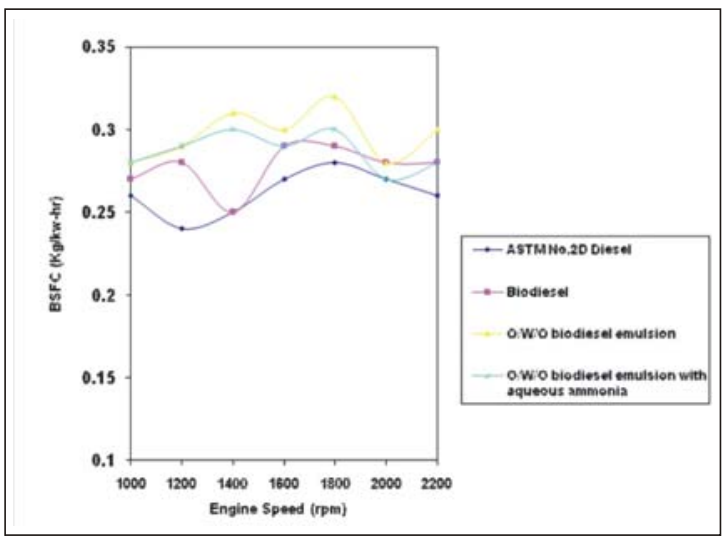

Fig. 3. The variation of BSFC with load for different fuels 
The variations of equivalence ratios with load for different fuels is presented in Fig 4. For all fuels tested, equivalance ratio is found to increase in increase in load, because of the increase in the fuel consumption rate.

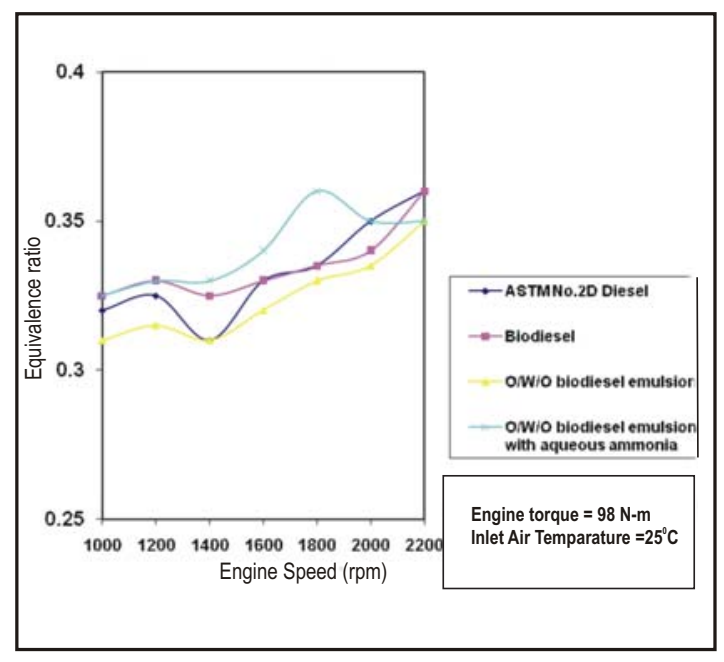

Fig. 4. The variation of Equivalence ratio with load for different fuels

Although the biodiesel and biodiesel emulsions requires larger fuel consumption rates than the ASTM No.2D diesel fuel to attain the same engine power output, the equivalance ratios of the heat biodiesel and the o/w/o emulsion were comparable with those of the ASTM No.2D diesel fuel. Since biodiesel contains $9.94 \mathrm{wt} \%$ oxygen content, causes less consumption of oxygen in reacting air and thus the more un-reacted oxygen and a larger excess air concentration in the exhaust gas. Hence, both an increase of the fuel consumption rate and excess air occurred when the biodiesel and o/w/o biodiesel emulsions were used as the engine fuel. Moreover, there is no obvious difference in the equivalence ratio among the four fuels.

Engine torque $=98 \mathrm{~N}-\mathrm{m}$

Inlet air temperature $=25^{\circ} \mathrm{C}$

Fig. 5. compares the $\mathrm{CO}_{2}$ emission of various fuels used in the diesel engine. For good combustion, all carbon must come as $\mathrm{CO}_{2}$ in the exhaust but the situation is different. All carbon in the fuel cannot be converted to $\mathrm{Co}_{2}$. But in case of biodiesel, additional $\mathrm{O}_{2}$ present helps combustion compared to diesel. The $\mathrm{CO}_{2}$ emmission increase with increases in load.

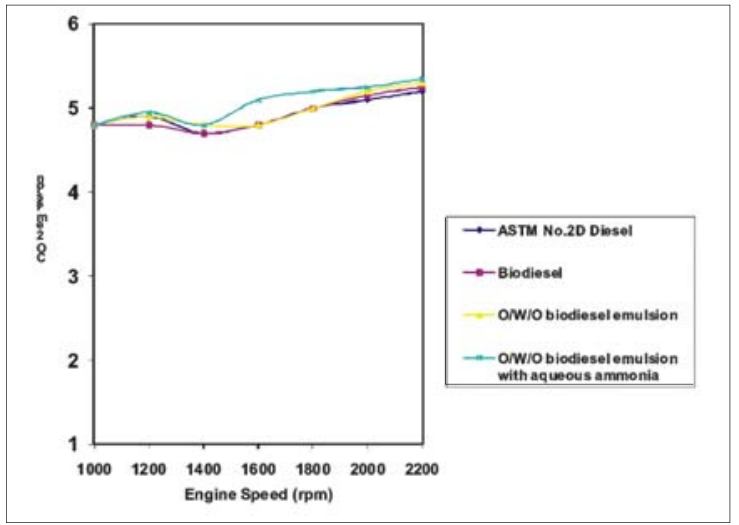

Fig. 5. The variation of Carbon dioxide emissions with load for different fuels

But o/w/o biodiesel emission level is lower than that of the diesel mode. More amount of $\mathrm{CO}_{2}$ in exhaust emission is an indication of the complete combustion of fuel. This supports the higher value of exhaust gas temperature. The combustion of fossil fuels produces carbon dioxide, which are getting accumulated in atmosphere and leads to many environmental problems. The combustion of biodiesel includes carbon dioxide but crops are readily absorbing these and hence carbon dioxide levels are kept in balance.

The variation of exhaust gas temperature with respect to applied load for different fuels tested is shown in Fig 6 . The o/w/o biodiesel emulsion also contains some amount of oxygen molecules in the ester form. It is also taking part in the combustion. Exhaust gas temperature indicates the burning efficiency. In diesel engine, there are four stages in combustion process. After burning stage is more or engine misfires or injection time is not proper then there is every possibility that EGT may be high. On the other hand, if the combustion process is perfect, then also exhaust gas temperature is likely to be high. It may be observed that thermal efficiency is more in case of o/w/o biodiesel emulsion and this leads to a probable conclusion that the combustion process is better. The burning of the ASTM No.2D diesel fuel appears to have a slightly larger exhaust gas temperature, particularly at higher engine speeds, primarily because of its higher heating value and lower amount of oxygen than the other three fuels. Moreover, micro-explosion shortened the burning time and thus decreased the exhaust gas temperature. 


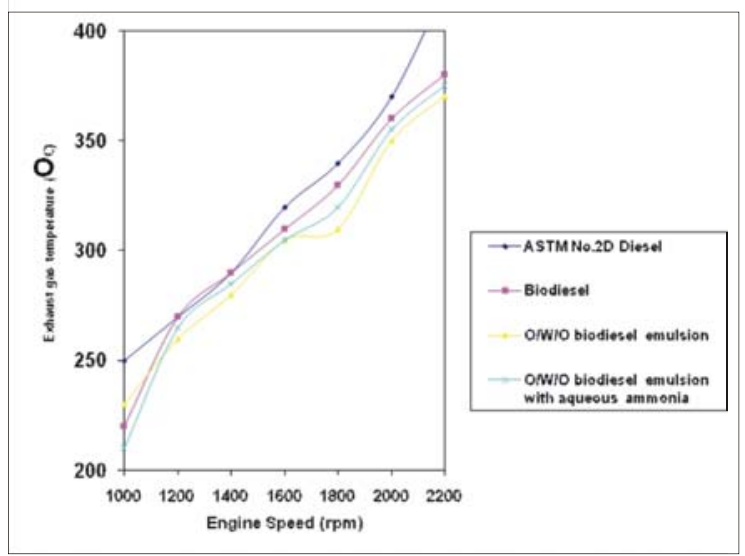

Fig. 6. The variation of Exhaust gas temperature with load for different fuels

The emission characteristics of biodiesel are of special interest in relation to meeting the environmental norms. Fig. 7 shows the plots of carbon monoxide emission of the ASTM NO.2D diesel and biodiesel emulsion operation at the rated engine speed of 1500rpm at various load conditions. The fuels are producing low amount of carbon monoxide emission at lower load levels and are giving more emission at higher loading conditions. The carbon monoxide emission are found to be increasing with increase in load, carbon emission depends upon combustion efficiency and carbon content of the fuel which during combustion undergoes a series of oxidation and reduction reactions. Carbon content of fuel is oxidized with $\mathrm{O}_{2}$ available in the air to $\mathrm{CO}$ and then to $\mathrm{CO}_{2}$. Carbon, which is not converted to $\mathrm{CO}_{2}$, will come back as $\mathrm{CO}$ in the exhaust. The $\mathrm{CO}$ emissions from buring the ASTM No.2D diesel fuel and the heat biodiesel appear to decrease with the increase of the engine speed, whereas those from buring the o/w/o emulisons both with and without aqeous ammonia increase.

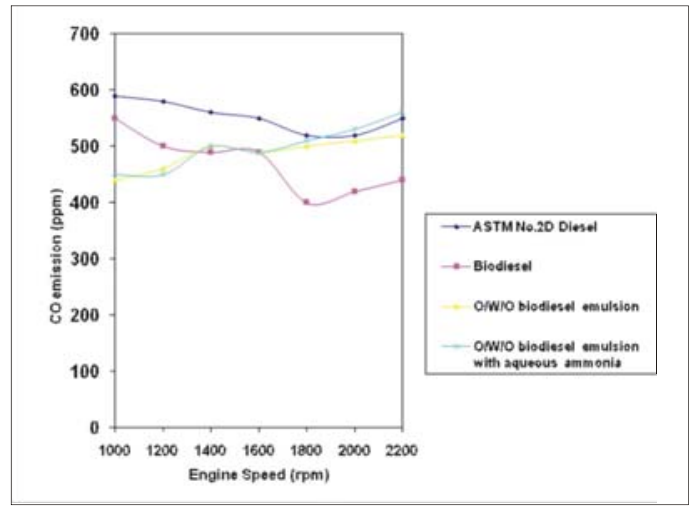

Fig. 7. The variation of Carbon monoxide emission with load for different fuels
For diesel fuel, the most important pollutants are smoke and $\mathrm{NO}_{x}$ emisssions. From the $\mathrm{NO}_{x}$ curves Fig 8 , two important observations are made. This is expected because with increasing load, the temperature of the combustion chamber increases and $\mathrm{NO}_{x}$ formation is a strongly temperature dependent phenomenon. Second important observation is that the $\mathrm{NO}_{x}$ emissions in the case of biodiesel fuel are higher by approximalety 6 percent. These higher $\mathrm{NO}_{x}$ emissions may be due to higher temperatures of the combustion chamber using biodiesel. This is also evident from exhaust temperature from the

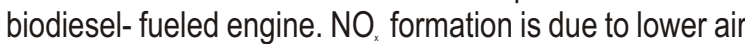
entrainment and fuel air mixing rates. $\mathrm{NO}_{x}$ are formed inside a diesel engine due to high flame temperature, peak presure inside the cylinder, nitrogen content of the parent fuel and the residence time of the fuel inside the cylinder. As the cetane number of the o/w/o biodiesel emulsion is high compared to diesel, the residence time or ignition delay may be less in case of biodiesel emulsion. Once again the oxygen content of the fuel enhances the ignition quality, thereby reduced delay period of biodiesel emulsion. This may be the probable reason for low $\mathrm{NO}_{x}$ in case of biodiesel emulsion.

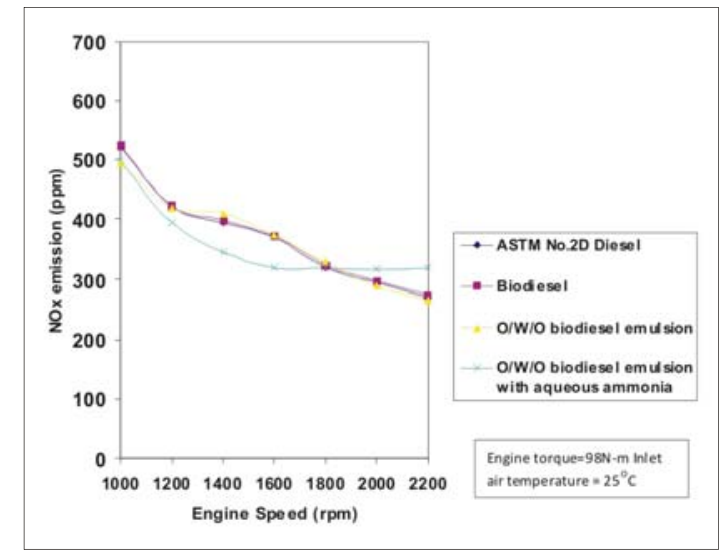

Fig. 8. The variation of Nitrogen oxide emission with load for different fuels

The neat biodiesel produced lower $\mathrm{NO}_{\mathrm{x}}$ emissions because it had a lower heating value than that of the ASTM No.2D diesel. The $\mathrm{NO}_{\mathrm{x}}$ emission were most effectively curtailed by burning the o/w/o three-phase biodiesel emulsion that contained aqeous ammonia, particularly at lower engine speeds. However, they remained nearly constant at engine speeds higher than 1500rpm and slightly increased with the engine speeds when they were higher than $1 \& 2000 \mathrm{rpm}$. This probably occurred because the high injection pressure of the emulsion and high feeding fuel temperature accelerated the oil-water separation between the o/w phase and the outer oil phase. The content of aqeous ammonia was therafter gradually 
separated from the o/w/o biodiesel emulsion so that its inhibiting effect on $\mathrm{NO}_{x}$ formation was reduced. In consequence, the $\mathrm{NO}$ emission remained invariant at medium and higher engine speeds for the o/w/o biodiesel emulsion that contained aqeous ammonia.

\section{CONCLUSION}

Four fuels, including heat biodiesel, three phase o/w/o biodiesel emulsion,o/w/o biodiesel emulsion that contained aqeous ammonia (which is a $\mathrm{NO}$, inhibitor agent), and ASTM No.2D diesel fuel were tested in a direct injection diesel engine. The experimental results are summarized as follows.

Based on the exhaustive engine tests, it can be concluded that biodiesel can be adopted as an alternative fuel for the existing conventional diesel engines without any major modifications required in the system hardware. The effects of biodiesel emulsification and $\mathrm{NO}_{x}$ inhibitor agents on diesel engine performance and biodiesel emission characteristics are investigated in this study. Esterification is a process, which brings about a change in the molecular structure of the vegetable oil reduces substantially after esterification. Esterification accompanied by peroxidation has been found to be an effective technique to prevent some long- term problems associated with utilization of vegetable oils such as fuel filter plugging, injector cooling, formation of carbon deposits in combustion chamber, ring sticking,and contamination of lubricating oils. The fuel consumption rate brake specific fuel consumption (BSFC), equivalance ratio, $\mathrm{CO}_{2}$ emissions, and exhaust gas temperature increase with the increase of engine speed, whereas $\mathrm{NO}_{*}$ emissions decreased. All these tests for performance and characterization of biodiesel oil demonstrated that almost all the important properties of biodiesel oil demonstrated that almost all the important properties of biodiesel are in very close agreement with the diesel oil making it a potential candidate for the application in compression ignition engines for $\mathrm{CO}$ emissions with the engine speed was adverse the emission decreased with the engine speed for the ASTM No.2D diesel fuel and with the biodiesel, but increased for the o/w/o biodiesel emulsions and the biodiesel emulsion that contained aqeous ammonia.

A diesel engine can perform satisfactorily on biodiesel fuel without any engine hardware modifications. Larger fuel consumption rates and BSFC were required to maintain the same engine power output for the heat biodiesel and the o/w/o biodiesel emulsions than for the ASTM No.2D diesel fuel.

The carbon deposits on piston top and injector cooling substantially reduced in biodesel fueled system.
In addition the o/w/o biodiesel emulsions appeared to have the larger kinematic viscosity, fuel consumption rates, and BSFC but the lowest heating value, $\mathrm{CO}$, emissions, and exhaust gas temperature. There was a high significant difference in the equivalance ratio among the various fuels. The o/w/o biodiesel emulsion that

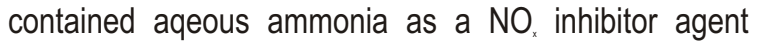
produced the lowest $\mathrm{NO}_{x}$ emissions among the fuels. The performance of o/w/o biodiesel emulsion that contained aqeous ammonia was marginally better than the dieselfueled engine in terms of thermal efficiency, brake specific energy consumption, wear of vital components, and exhaust emission for entire range of operations.

NO, formation is mainly because it is highly temperature dependent phenomenon. Fuel emulsification and the use of $\mathrm{NO}_{x}$ inhibitor agent were shown to be effective in curtailing $\mathrm{NO}$, emissions for biodiesel in this study. A larger fuel consumption rate and larger brake specific fuel consumption than the neat biodiesel were required due to the lower heating value of the biodiesel emulsions that contained water of 10 volume $\%$.

\section{REFERENCES}

[1] A Sharma, S.K Khare, M.N Gupta, Zooga. "Three phase partitioning for extraction of oil form soybean". Bioresour, Technol. 85, pp.327-329.

[2] H.P.S Makkar, K Becker, F.Sporen, M Wink, 1997. "Studies on nutritive potentioal and toxic constituents of different provenances of Jatropha curcas L." J. Agric. Food chem.45, pp. 3152-3157.

[3] A Rosenthal, D.L Pyle, K.Niranjan, 1996. "Aqeous enzymatic processes for edible oil extraction". Enzyme Microb. Technol.19, pp.402-420.

[4] G.M Gubitz, M Mittelbach, M Trabi, 1999, "Exploitation of the tropical oil seed plant Jatropha curcas L." Bioresour Technol. 67, 73-82.

[5] G.A Stewart, , W.H.M Rawlins, G.R Quick, J.E Begg,. \& W.J Peacock,. 1981. "Oil seeds as a renewable source of diesel fuel". Search, 12. 107 (and references cited therein).

[6] R Bhasabutra,. \& S Sutipoonpeibun, 1982. "Jatropha curcas oil as a substitute for diesel engine oil." Renewable Energy Review Journal,4,56.

[7] Anon, 1959," Wealth of India, raw materials", Vol. V, New Delhi, 293 CSIR.

[8] Gubitz GM, et al ., editors, 1997 "Bio fuels and industrial products from Jatrpha curcas". Proceedings from a symposium held in Managva, 
Nicaragua. Graz, Austria: Technical University of Gruz,

[9] J. Heller,1996, "Physic nut, Jatropha curcas. Promoting the conservations and use of underutilized and neglected crops". Rome, Italy: International Plant Genetic Resources. Institute (IPGRI),

[10] R. Heening, 1996, The Jatropha Project in Mali. Weissenberg. Germany : Roth kreuz 11, D-88138,

[11] GTZ. Plant oi, 1995, I : A contribution to energy issues and sustainable development. Germany.

[12] Eschborn65760, GTZ/ Rockfeller foundation. 1995.The plant oil initiative. Newyork: Rock feller foundation,

[13] Jones N, Miler JH, 1992 "Jatropha curcas : a multipurpose species for problematric sites". Washington DC : The world bank.

[14] Newsletter Plant oil, 1993, "Engine Development Group". Issue Vol.1. Harare, Zimbabwe : Plant oil \& Engine Development Group.

[15] Zimbabwe Biomass News, 1996, Plant oil : Zimbabwe sustainable fuel for the future. Vol.1, No.2. Cause way, Zimbabue: BUN-Zimbabwe.

[16] M A Fanguri and M A Hanna, 1999, "Biodiesel production: A review", Biores Technol, 70, pp.1-15.
[17] W.Korbitz, 1999, "Biodiesel Production in Europe and North America, an Encouraging Prospect", Renewable Energy, 16, pp. 1078-1083

[18] T.Krawezyk, 1996, "Biodiesel, alternative fuel makes in roads but hurdles remain", Inform, 7 , pp. 801-814.

[19] AS Ramadass, S Jayaraj, C Muraleedharan, 2005, "Biodiesel Production from high FFA Vegetable oil", Fuel, 84, pp. 335-40.

[20] SV Ghadge, H Rahemen, 2005 "Biodiesel production from Mahua (Madhumica Indica) Oil having high fee fatty acids", Biomass Bioenergy; 28 , pp. 601-5.

[21] ARecep, C Selim, S YHuseyin, 2001," The potential of using Vegetable oil fuels as fuel for diesel engines". Energy convers manage; 42.

[22] NDS Fernando, SP Antonio, RT Jorge, 2003, "Technical feasibility assessment of oleic sunflower methyl ester utilization in diesel bus engines". Energy Covers Manage; 44.

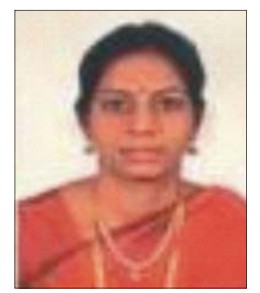

Manjula is a research scholar and a Senior Lecturer in the Department of Chemical Engineering, Sathyabama University, Chennai. She is a postgraduate in Petroleum Refining and Petrochemicals at Anna University, Chennai, India. 